\title{
Prenatal supply of docosahexaenoic acid (DHA): should we be worried?
}

\author{
Berthold Koletzko* \\ Department of Paediatrics, Dr. von Hauner Children's \\ Hospital, University of Munich, Germany
}

Sir,

In her insightful and very informative review [6], Hadders-Algra proposes that

1) the supply of docosahexaenoic acid (DHA) without concomitant arachidonic acid (AA) in early pregnancy might induce an $A A$ depletion in tissues and thus should not be recommended, and

2) the evidence for benefits of prenatal DHA is weak.

While the review is extremely thoughtful and reflects the deep insights of the author into the field, the two assumptions cited above need be challenged. We fully agree with Hadders-Algra that AA has its own potent and biologically important functions, which makes it unwise to support interventions markedly reducing tissue levels of $A A$, but we do not have evidence for any such risk with a DHA supply in the currently recommended dosage near $200 \mathrm{mg} /$ day $[13,15]$.

Both AA and DHA are formed by endogenous conversion of the precursor essential fatty acids, linoleic acid and alpha-linolenic acid, respectively [17]. However, AA is synthesised via a rather short enzyme catalised pathway of only two desaturation and one elongation steps, whereas the synthesis of DHA from alpha-linolenic acid is very long, complex and indirect [17]. Accordingly, numerous studies using assessment of blood levels or stable isotope turnover methodology indicate that the endogenous synthesis of $A A$ is far more effective than DHA, resulting in a much greater metabolic control and stability of AA than of DHA levels in human blood and

\footnotetext{
*Corresponding author:

Berthold Koletzko, MD

Professor of Paediatrics

Department of Paediatrics

Dr. von Hauner Children's Hospital

Ludwig-Maximilians University of Munich

Lindwurmstr. 4

DE-80337 Muenchen

Germany

Tel.: +49-89-5160-3967

Fax: +49-89-5160-3336

E-mail: Berthold.Koletzko@med.uni-muenchen.de
}

tissues. For example, infants that either do or do not receive preformed $\mathrm{DHA}$ and $\mathrm{AA}$ differ in blood levels of both fatty acids in the first months of life, whereas at the end of the first year of life AA but not DHA levels are equal, indicating a greater degree of endogenous metabolic control of AA than of DHA levels [14]. Moreover, single nucleotide polymorphisms of the enzymes delta- 6 and delta-5 desaturase involved in the synthesis of both AA and DHA predict about $28 \%$ of the variation of $A A$ levels in plasma phospholipids of free living adults, but only $1.4-2.9 \%$ of the DHA variation [20]. This leads to the conclusion that humans have a far higher ability for homeostatic regulation of stable AA than of DHA levels. This reasoning is further underpinned by the observation of a rather narrow range of $A A$ levels in human milk worldwide, in spite of considerable differences in dietary intake of AA, whereas milk DHA levels vary widely with diet of the lactating women [1].

Indeed, the supplementation of women of childbearing age with a large dose of about $1 \mathrm{~g} \mathrm{DHA}$ /day in a randomised trial led to a large, 2.6-fold increase of plasma phospholipid DHA levels over 8 weeks, whereas there was only a minimal change of AA $(-10 \%$ of baseline levels) [4]. Similarly, the daily supplementation of $500 \mathrm{mg}$ DHA plus $150 \mathrm{mg}$ eicosapentaenoic acid (EPA) to pregnant women in a randomised multicentric trial led to significantly increased DHA values in placenta as well as maternal and cord blood lipids, whereas AA levels were unchanged $[12,20]$. The fatty acid composition of infant brain responded to a postnatal dietary DHA supply (from breast milk compared to infant formula without DHA or $\mathrm{AA}$ ) with an increase of DHA incorporation, whereas brain AA levels were unaffected by diet [5]. Thus, AA levels in blood and tissue are relatively stable.

Reassurance on the safety of provision of DHA without AA is also provided by recent meta-analyses of randomised controlled trials on supplementation of pregnant women with oils providing either DHA or the combination of EPA and DHA, but without added AA, which found no indications of untoward effects of supplementation up to daily dosages of $1 \mathrm{~g}$ DHA, $2.7 \mathrm{~g}$ omega 3 LC-PUFA, or 5-6 g fish oil [9, 18, 21]. Cohort studies evaluating habitual intake of fatty fish provides ample DHA and EPA but little AA throughout pregnancy, also found no adverse effects but rather benefits on child outcome [8, 19]. Self selected habitual intake reflects dietary habits and intake throughout pregnancy. 
The second important question is whether there are reasonable indications for benefit of a DHA supply to pregnant women to support the provision of this conditionally essential nutrient. Recent systematic reviews and meta-analyses of randomised controlled trials (RCT) concluded that the provision of long-chain omega-3 fatty acids from fish oils (DHA plus EPA) or single cell oils $(\mathrm{DHA})$ reduce the likelihood of early preterm birth before 34 weeks of gestation by $31 \%$ in all pregnancies or by $61 \%$ in pregnancies at risk $[9,18]$, which translates into a major benefit with respect to reducing infant morbidity and mortality.

With respect to reported effects of fish consumption (providing dietary DHA) or the supplementation of DHA rich oils on developmental outcome, it is not surprising that different results have been reported, given the large differences in interventions and dosages used, different populations, and huge differences in the choice of outcomes measured as well as the time points of assessment, and large variation in methodology [2]. However, while studies have reported either positive or neutral effects on child developmental outcomes, there are hardly any negative results reported with DHA supply to pregnant women, yielding an overall positive balance [2]. For example, results from a large observational cohort study assessing fish intake during pregnancy in more than 11,000 women showed that an increased maternal seafood consumption was associated with strong beneficial effects on development of verbal IQ, fine motor function and social behaviour in the children which were tested up to the age of 8 years [8]. A dose-response relationship was found between the amount of seafood consumed and later verbal IQ development, with close to optimal outcomes at a fish intake providing approximately 200 mg DHA per day. Similarly, a prospective cohort study in New England found improved cognitive outcomes in children, assessed by visual recognition memory testing, with higher maternal fish consumption during pregnancy [19]. For each additional weekly fish serving, the child's visual recognition memory score was four points higher. In addition, beneficial effects on cognitive development of infants and children were found in recent RCTs on the effects of DHA supplementation during pregnancy and lactation. The provision of high dose fish oil to pregnant women in a double blind RCT showed improved eye-hand coordination in the offspring at the age of 2.5 years [3]. Another double blind RCT tested maternal supplementation during pregnancy and lactation with cod liver oil providing about $1.2 \mathrm{~g} \mathrm{DHA}$ and $0.8 \mathrm{~g}$ EPA, which led to a $4 \%$ point advantage in children's scores on a standardised Kaufmann ABC intelligence test in children tested at the age of 4 years [7]. A recent double blind $R C T$ randomised pregnant women to placebo or supplementation with $300 \mathrm{mg}$ DHA per day, which improved infant problem-solving at 9 months of age [10]. While Hadders-Algra is certainly correct in concluding that many more carefully controlled trials should be performed, and more detailed developmental testing of children in relation to maternal dietary lipid intake is highly desirable, the available data support the conclusion that the provision of DHA from adequate sources during pregnancy without concomitant supplementation of $A A$, has no known adverse effects and can provide relevant benefits.

Based on the available evidence, experts from a large number of international scientific organisations advise that pregnant and lactating women should aim at achieving an average intake of 200 mg DHA/day, and concluded that no evidence exists that women of childbearing age with an adequate dietary intake of linoleic acid (from vegetable oils) would need an additional dietary intake of $\mathrm{AA}[13,15]$

\section{Acknowledgements}

The work of the author has been carried out with partial financial support from the Commission of the European Communities, within the $5^{\text {th }}$ Framework Programme, project PERILIP QLK12001-00138 and the $6^{\text {th }}$ Framework Programme, The Early Nutrition Programming Project, contract no. 007036. This manuscript does not necessarily reflect the views of the Commission and in no way anticipates the future policy in this area. Additional support from the Child Health Foundation, Munich, is gratefully acknowledged. BK is the recipient of a Freedom to Discover Award of the Bristol-Myers-Squibb Foundation, New York, NY, USA.

\section{References}

[1] Brenna JT, Varamini B, Jensen RG, Diersen-Schade DA, Boettcher JA, Arterburn LM. Docosahexaenoic and arachidonic acid concentrations in human breast milk worldwide. Am J Clin Nutr. 2007;85:1457-64.

[2] Cetin I, Koletzko B. Long-chain omega-3 fatty acid supply in pregnancy and lactation. Curr Opin Clin Nutr Metab Care. 2008, in press.

[3] Dunstan JA, Mori TA, Barden A, Beilin JT, Taylor AL, Holt $P G$, et al. Fish oil supplementation in pregnancy modifies neonatal allergen specific immune responses and clinical outcomes in infants at high risk of atopy: a randomized controlled trial. J Allergy Clin Immunol. 2003;112:1178-84.

[4] Geppert J, Kraft V, Demmelmair H, Koletzko B. Microalgal docosahexaenoic acid decreases plasma triacylglycerol in normolipidaemic vegetarians: a randomised trial. $\mathrm{Br} \mathrm{J}$ Nutr. 2006;95:779-86.

[5] Gibson RA, Neumann MA, Makrides M. Effect of dietary docosahexaenoic acid on brain composition and neural function in term infants. Lipids. 1996;31 Suppl:S177-81.

[6] Hadders-Algra N. Prenatal long-chain polyunsaturated fatty acid status: the importance of a balanced intake of docosahexaenoic acid and arachidonic acid. J Perinat Med. 2008;36:101-9.

[7] Helland IB, Smith L, Saarem K, Saugstad OD, Drevon CA. Maternal supplementation with very-long-chain $n-3$ fatty acids during pregnancy and lactation augments children's IQ at 4 years of age. Pediatr. 2003;111:e39. 
[8] Hibbeln JR, Davis JM, Steer C, Emmett P, Rogers I, Williams $C$, et al. Maternal seafood consumption in pregnancy and neurodevelopmental outcomes in childhood (ALSPAC study): an observational cohort study. Lancet. 2007;369: 578-85.

[9] Horvath A, Koletzko B, Szajewska H. Effect of supplementation of women in high-risk pregnancies with long-chain polyunsaturated fatty acids on pregnancy outcomes and growth measures at birth: a meta-analysis of randomized controlled trials. Br J Nutr. 2007;98:253-9.

[10] Judge MP, Harel O, Lammi-Keefe CJ. Maternal consumption of a docosahexaenoic acid-containing functional food during pregnancy: benefit for infant performance on problem-solving but not on recognition memory tasks at age 9 mo. Am J Clin Nutr. 2007;85:1572-7.

[11] Klingler M, Demmelmair H, Larqué E, Koletzko B. Analysis of fatty acid contents in individual lipid fractions from human placental tissue. Lipids. 2003;38:561-6.

[12] Klingler M, Blaschitz A, Campoy C, Cano A, Molloy AM, Scott JM, et al. The effect of docosahexaenoic acid and folic acid supplementation on placental apoptosis and proliferation. Br J Nutr. 2006;96:182-90.

[13] Koletzko B, Cetin I, Brenna JT, for the Perinatal Lipid Intake Working Group. Dietary fat intakes for pregnant and lactating women. Br J Nutr. 2007;98:873-7.

[14] Koletzko B, Sauerwald T, Demmelmair H, Herzog M, von Schenck U, Böhles $H$, et al. Dietary long-chain polyunsaturated fatty acid supplementation in infants with phenylketonuria: a randomized controlled trial. J Inherit Metab Dis. 2007;30:326-32.

[15] Koletzko B, Lien E, Agostoni C, Böhles H, Campoy C, Cetin I, et al. The roles of long-chain polyunsaturated fatty acids in pregnancy, lactation and infancy: review of current knowledge and consensus recommendations. J Perinat Med. 2008;36:5-14.

[16] Krauss-Etschmann S, Shadid R, Campoy C, Hoster E, Demmelmair $\mathrm{H}$, Jimenez $\mathrm{M}$, et al. Effects of fish-oil and folate supplementation of pregnant women on maternal and fetal plasma concentrations of docosahexaenoic acid and eicosapentaenoic acid: a European randomized multicenter trial. Am J Clin Nutr. 2007;85:1392-400.

[17] Larqué E, Demmelmair H, Koletzko B. Perinatal supply and metabolism of long-chain polyunsaturated fatty acids: importance for the early development of the nervous system. In: Klimes I, Sebökova E, Howard BV, Ravussin E, editors. Lipids and insulin resistance. The role of fatty acid metabolism and fuel partitioning. Annals New York Acad Science. 2002;967:299-310.

[18] Makrides M, Duley L, Olsen SF. Marine oil, and other prostaglandin precursor, supplementation for pregnancy uncomplicated by pre-eclampsia or intrauterine growth restriction. Cochrane Database Syst Rev. 2006;19: CD003402.

[19] Oken E, Wright RO, Kleinman KP, Bellinger D, Amarasiriwardena $\mathrm{CJ}, \mathrm{Hu} \mathrm{H}$, et al. Maternal fish consumption, hair mercury, and infant cognition in a U.S. cohort. Environ Health Perspect. 2005;113:1376-80.

[20] Schaeffer L, Gohlke H, Müller M, Heid IM, Palmer LJ, Kompauer I, et al. Common genetic variants of the FADS1 FADS2 gene cluster and their reconstructed haplotypes are associated with the fatty acid composition in phospholipids. Hum Mol Genet. 2006;15:1745-56.

[21] Szajewska H, Horvath A, Koletzko B. Effect of n-3 longchain polyunsaturated fatty acid supplementation of women with low-risk pregnancies on pregnancy outcomes and growth measures at birth: a meta-analysis of randomized controlled trias. Am J Clin Nutr. 2006;83:1337-44. 